\title{
Educational intervention for Caregivers about Intestinal Parasitic Infestations for First Year Primary School Students in Minia City.
}

\author{
Naglaa Mohammed Amein, Soheir Ali Abed El-Hady Bader EL-Din, Soad Sayed Bayomi, \& Yosria EL-sayed \\ Hossein.
}

Department of , community health nursing- faculty of nursing, EL-Minia university, Department of , community health nursing- faculty of nursing- Cairo university, - Department of , community health nursing- faculty of nursing Assiut university.

\begin{abstract}
:
Parasitic infestations are serious public health problem that lead to physical and mental health problems such as iron deficiency anemia, growth retardation, and lack of concentration. The current study aimed to evaluate the effect of an educational intervention for caregivers about intestinal parasitic infestations for first year primary school students at EL-Minia city. Quasi-Experimental research design was utilized in the current study. The study was conducted in four primary governmental schools at EL-Minia city. Multi stage random sample techniques were used in this study. Data were collected using structured interview questionnaire to assess caregiver's knowledge about intestinal infestation, Observational check list for asses house environmental through home visit, observational check list to asses caregivers practice and Attitude scale to assess the caregiver's attitude regarding the safety food. The study result evident that there was a highly statistically significant difference between the caregivers' knowledge about intestinal infestation in pre, post test and follow-up ( $\mathrm{P}$ value $=0.001)$. Also, there with highly statistically significant difference between caregivers and practices in pre and post test $(\mathrm{p}=0.001)$, the majority of caregivers agree the food eating is healthy in pre test decreased to $95.0 \%$ on post test, with statistically significant difference $(p$ value $=0.04)$. The present study concluded that the educational intervention there with significant improvement of knowledge, practices and attitudes of caregivers regarding intestinal parasitic infestations. It was recommended that periodical educational intervention should be implemented for caregivers of the primary school children at Upper Egypt regarding intestinal parasitic infestation to improve knowledge and practices.
\end{abstract}

Keywords: parasite, intestinal infestation, hygienic measures,

\section{Introduction:}

Intestinal infestations are common cause of health problems in developing countries. It is estimated that at least one quarter of the world's population is chronically infected with intestinal parasites and 1.5 to 2.7 million deaths annually (WHO, 2009).

Intestinal infestations are amongst the common infections worldwide, it is estimated that about 3.5 billion people are affected, and that 450 million are ill as a result of these infestations, the majority are being children. School age children are important target group in the community health because their physical and emotional health is vital to the future of society and they require guidance and direction. Children are vulnerable to many illness, injuries, emotional problem as a result of a complex and stressful environment, especially intestinal infestations (Allender et al., 2010).

School children carry the heaviest burden of morbidity due to intestinal infestations, it is estimated that approximately $70 \%$ of the disease burden on whole population can be prevented in high prevalence communities by treating school children alone (Chan, 2004\& Nies and McEwen, 2011).
Intestinal infestations are among the major diseases of public health problems in sub-Saharan Africa. Apart from causing mortality and morbidity, infection with intestinal parasites has been associated with stunting major of linear growth, physical weakness and low educational achievement in schoolchildren (Erko and Legesse, 2004).

Parasitic infestations have great impact on life quality of people all over the world especially in developing countries; the prevalence of parasitic infections in a particular region depends not only on bioenvironmental situation, but also on social, economical and cultural conditions, in developing Countries that are mainly situated in tropical areas, lack of access to health services, malnutrition, and poor sanitation, increase vulnerability to infection because of physiological and immunological reasons children more susceptible to parasitic infestation (Hazrati Tappeh et al., 2010 \& Borg and Ryan, 2010).

The Governorate of Qena, in Upper Egypt, ranks 16 out of the 21 governorates in Egypt for which Health development Indicators are available, although intestinal helminthes are considered to be prevalent in the governorate, there is a complete lack of data on 
types of parasites present and their prevalence, the most common intestinal helminthes in the world are Ascarisis lumbricoides round worm, they are usually referred to as soil-transmitted helminthes since they are most commonly disseminated by contamination of soil and environment with infected faeces, especially by children. Three helminthes present in Egypt are Enterobius vermicularis, Hymenolepis nana and tape worm). Their effects on child development appear less serious (Curtale et al., 2009).

Significance of the study\& role of Community Health Nursing:

Through research in El-Minia city finding in 1800 case affected with parasitic infestation, this result obtained from Preventive Medical Department in administrative health in west medical center .This result at 2010 and also 2012. Related this result found intestinal infestations are community health problem and more spreading at El - Minia City. In Egypt, $56.0 \%$ and $47.0 \%$ of children are worryingly suffering from intestinal parasites and anemia, respectively in further detail $40.4 \%$ and $1.9 \%, 5.4 \%, 6.3 \%, 8.7 \%$, $8.9 \%, 22.4 \%$, of the Egyptian school children were suffering from Enterobius vermicularis, Schistosoma (S.) haematobium, Giardia lamblia, S. mansoni, Ascaris lumbricoides Entamoeba (E.) histolytica and Ancylostoma duodenale, respectively.

Community health nursing should play an essential role in supporting caregivers and increase awareness about how to deal with infected children with intestinal parasitic infestations through families, and community (Bogitsh et al., 2013)

Aim of the study:

This study aims to:

- Evaluate the effect of an educational intervention for caregivers about intestinal parasitic infestations for first year primary school students at EL-Minia city. Through

- Assessing the caregiver knowledge about intestinal infestation.

- Assessing the hygienic measures of home environment and the caregiver's practices.

Research hypotheses:

-Designing and implementing educational intervention program according to their needs

-Evaluating the knowledge and practice improvement after program

\section{Subjects and Methods}

\subsection{Research Design:}

Quasi-Experimental research design was utilized in the current study.

5.2 Subject:

- Multistage random sample techniques were used in this study.
- First stage: four primary governmental schools were chosen from 42 schools of 4 sectors in Minia city

- Second stage: one class were selected from each school ( $1^{\text {st }}$ year primary) the total classes were $1 / 1$, $1 / 3,1 / 2$ and 1/1 respectively of Saad Zaglol, Tark eben Ziad, Elfath and El-shaheed

-Third stage: 25 student's select of each class participate with their caregivers from school and home visit

-Four stage 100 caregivers have children in the first role primary participate in the study from the previous mention setting

\subsection{Setting:}

The study was conducted at four primary governmental schools. These were Saad Zaglol, Tark ebn Ziad, Elfath and EL-shaheed schools at ELMinia city.

\subsection{Tools of data collection:}

Data were collected through using the following tools:

A- Structured interview questionnaire they were designed by the researchers after reviewing the relevant literature, it was written in Arabic language and composed open and close ended questions to assess the following:

\section{Part (1):}

a) The demographic characteristics it includes (child age, child sex, residence, education and occupation of caregivers .......etc)

b) The Caregivers knowledge regarding the intestinal infestation and consists of the following: (definition, types of intestinal worm, cycle of Pin worm and Ascariasis, mode of transmission, prevention, treatment .etc)

Part 2:

It includes:

a) Asking question and school recode related to child care, place of playing, absent from school, irritability during sleep, healthy food, weight, types of drinking water.

b) Caregivers knowledge regarding the food safety in the house includes (presence of disease from the contaminated food, types of disease, causes of this disease, prevention etc.....

B- (Observational check list):

a) Observational check list was developed for assessing house environmental through home visit (cleanliness, ventilation, crowding, water supply, waste disposal, types of toilet, sewage disposal

b) Assessing the caregiver's practices through asking question \& really observation. The observation check list included certain items concerning environmental sanitation, hygienic measures \& health behaviors of the child and 
caregivers e.g.(hand washing, nail care, clothes hygiene, methods of washing vegetables and fruits )each items measuring between done/ not done .This tool used before and after the educational intervention to evaluate what extend the effectiveness of the program.

c) Attitude scale, (Rojas and Brewer, 2008)

Attitude scale was developed and modified by the researcher to obtain the necessary data under supervision of expertise of community department. It includes questions concerning food safety habits, responses by agree and disagree.

\section{Scoring system for knowledge, practice and}

\section{attitude}

Were calculated as the following: Knowledge: The level of knowledge was then categorized into three categories as following:

1. Those with scores of $<50 \%$ were considered having poor knowledge.

2 . Those with scores of $>50-75 \%$ were considered having fair knowledge

3. Those with scores of $>75 \%$ were considered having good knowledge

a-parasitic infestation: its questions were recorded into know with score 1 and do not know with a score 0 and the total score was ranged from $0-15$ and classified as the following: Poor = less than $50 \%$ (7 or less).Fair $=50-75 \%(\geq 8-12)$. Good $=$ more than $75 \%$ (>_13-15) .b- food sanitation: its questions were recorded into know with score 1 and do not know with a score 0 and the total score was ranged from $0-8$ and classified as the following: Poor $=$ less than $50 \%$ (4 or less).Fair= $50-75 \%(\geq 5-6)$. Good =more than $75 \%\left(>\_7-8\right)$.

b-Practice: a- Food sanitation: its questions were recorded into done with score 1 and not done with a score 0 and the total score was ranged from 0-9 and classified as the following: Poor $=$ less than $50 \%$ (5 or less).Fair $=50-75 \%(\geq 6-7)$. Good $=$ more than $75 \%$ (>_7- 9). B- Personal hygiene: its questions were recorded into done with score 1 and not done with a score 0 and the total score was ranged from 1-16 and classified as the following: Poor $=$ less than $50 \%$ (8 or less). Fair $=50-75 \%$ $(\geq 9-12)$.Good $=$ more than $75 \%$ (>_13-16).

Attitude: its questions were recorded into agree with score 1 and disagree with a score 0 and the total score was ranged from 0-10 and classified as the following: Poor $=$ less than $50 \%$ (5 or less).Fair $=50-75 \%(\geq 5-$ $7)$. Good $=$ more than $75 \%(>7)$. $\%$ the probability of less than 50 was used as a cut off point for all significant tests.

Scores obtained on knowledge and practices of studied caregivers were used to make the required analysis before and immediate post-test and follow up at 3 months after the program. All statistical analyses were mainly computerized

\subsection{Validity test:}

- Data collection tools were developed by the researchers after extensive review of related recent literature .Tools were submitted to a panel of five experts in the field of community health nursing staff to test the content validity. Modification of the tools were done according to the panel judgment on clarity of sentences, appropriateness of content and sequence of items

Pilot study. A pilot study was conducted before starting of data collection; it was carried out on 10 caregivers of the total sample. Which was excluded from the studied subject to confirm question clarity and objectivity, and to estimate the interview time and its duration, some significant modifications were done to avoid the ambiguous of the questionnaires.

Field work:-

\section{Data collection procedure:}

An official letter from the Dean of Faculty of Nursing, El-Minia University, sent to Vice Ministry of Health and population to obtain the biostatistician data of parasitic infestations among children, and agreement of country safety, Vice of Ministry of Education then administrative directory of learning and education in El-Minia governorate for data collection was obtained. Then the approval given to every director of schools. This letter included the nature, importance and expected out comes of the study.

\section{The educational program Objectives}

a) To assess knowledge and practice of caregivers about intestinal parasitic infestation and its relation with hygienic measures

b) To assisting environmental factors, behavioral habits and complaints related to intestinal parasitic infestation.

c) To implement an educational intervention about parasitic infestations.

d) To evaluate the effect of an educational intervention upon the caregivers about intestinal infestations.

The program has been developed through four phases:-

Assessment phase: Based on the experience\& general knowledge about lake of knowledge and practices towered intestinal infestation, the educational intervention was developed to improve the caregiver's knowledge and practices, also based on pretest assessment which denoted knowledge deficit and unsatisfactory practices so the program media were prepared

Planning phase: The arrangement of conducting the program done; the sessions and time of the program decided. The study sample (caregivers) was divided 
into 10 groups in a variety of numbers ranged between (8-10) mothers in each group according to the numbers of sample in each place. Other facilities were checked and arranged as the teaching place, audiovisual aids, handout etc.......

Teaching Time: the teaching was decided according to coordination between the researchers and caregivers. Teaching place the program was conducted in the home or training room in each school those arrangements done with the director of each school. Teaching methods and materials: It was important before implementing the educational program to prepare simple teaching methods to be used; as lecture, discussion, and brainstorming. The media as power point presentation, blackboard, picture and handouts.

Implementation phase: - The educational program was conducted in one year starting from October 2011 until the end of October 2012 the researcher assesses the caregivers' needs before the educational intervention, this program continued for seven days to complete the program content for each group. The total numbers of sessions was (11), each day one or two session was to be given according to the planned course, after completed the program content followed by post test and finally follow up test done after three months from application of the program. Each interview took average 30 minutes. Throughout this interview relative information was recorded in the designed sheet depending upon the response of the participant. Every week about (2) sheet was finished (three days/week).

Evaluation phase: follow up which was don after completing the program

\section{Ethical consideration:}

The purpose of this study was explained for all caregivers. The caregivers have ethical rights to agree or refuse to participate in the study, oral consent was obtained from every caregivers. Also the probable benefits as well as the probable harm was clearly explained to the caregivers and informed that the information and data obtained will be confidential and used only for the purpose of the study. The participant's dignity and privacy was maintained and respected throughout the research process.

\section{Statistical design:}

Data entry and analysis were done with I.B.M. compatible computer using software called SPSS for windows version 11. Graphics were done by Excel. Quantitative data were presented by mean and standard deviation, while qualitative data were presented by frequency distribution. Chi square test and fisher exact were used to compare between proportions. One way ANOVA test was used to compare between means. The probability of less than 0.05 was used as a cut off point for all significant tests.

\section{Limitations of the study}

The researcher was faced with some obstacles before and during fieldwork. Some directors were uncooperative with the researcher. Also some caregivers refused to participate in the study because they had no enough time for the interview and need to meet with the researcher out of their time. Some participants were preoccupied with other duties.

\section{Results:}

Table (1): shows that the distribution of demographic characteristics for the school child and caregivers. The mean age of children was $6.9 \pm 0.6$, more than half of them were males and less than half were females. Also this table illustrates that less than half of caregiver's hade 4-6 children and $65.0 \%$ of children were first, as regards the order of the child in the family while $10.0 \%$ of them were came last, more than half of caregivers from urban area and $41.0 \%$ from semi urban. Regarding the levels of educations, it was clear $45.0 \%$ of caregivers were illiterate and only one tenth hade basic level of education. $73.0 \%$ of caregivers were house wives. As regards to income $38.0 \%$ of the caregivers earn for $400-799$ pounds a month and $30.0 \%$ of them earn more than 800 pounds / month.

Table (2): It shows that the majority of houses have electricity source, and $89 \%$ presnet ventilation in the house, regarding the source of water in the house $94 \%$ of the caregivers are using the tap water, and only $6.0 \%$ of them are using the pump water, most of the caregivers drinking water directly from the tap, and only $1.0 \%$ of them boiling the water before drinking it, and also the same number $1.0 \%$ of them drinking the distilled water, related to the type of toilet, $81.0 \%$ house toilet ordinary and $19.0 \%$ are modern. Regarding the source of water in the toilet, about two thirds $61.0 \%$ of the caregivers using the tap water directly in the toilet, while $39.0 \%$ of them are using the water in the container, regarding the sewage $92.0 \%$ present sewage in the house, and only $8.0 \%$ not present.

Table (3) : it cleared that more than half of the caregivers having animals in the home. Regarding animal's wastes disposal, $60.4 .0 \%$ disposes the animal wastes at the front in home and only $7.5 \%$ by governmental cares. $68.0 \%$ of the caregivers don't use any basket or container for home trash, 87.5.0\% of those baskets did not cover .Regarding frequency dispose of home trash more than half of the caregivers dispose the trash daily and only $11.0 \%$ weekly. Regarding housing sanitary condition this table illustrates that about two third of houses bad, 
$32.0 \%$ good and only $7.0 \%$ very good housing sanitary conditions

Table (4): reveled that more than two thirds $(67.0 \%)$ of caregivers washing hands before preparing the food in per test then increases to the majority $95.0 \%$ on post test and decreases again to 79.0 on follow up test, with statistically significant difference $(\mathrm{p}=0.001)$. Regarding to hands washing after eating $99.0 \%$ done after eating on post test and only $1.0 \%$ not done on post test, with highly statistically significant differences $(p=0.001)$. $47.0 \%$ of caregivers wash hands after leave the toilet in pre test and then increases to the majority $99.0 \%$ on post test, and these percent decrease again to $60.0 \%$ on follow up test, with statistically significant differences( $p=0.001)$.more than one third of caregivers wash hands with water only, more than half with water and soap, only $10.0 \%$ use disinfected solution in pre test while used soap and water elevated to $80.0 \%$ on post test,with statistically significant differences ( $p=0,001$, the majority $94.0 \%$ of caregivers didn't wash hands after dispose the home and animals wastes these percent decreased to $71.0 \%$, on post test and $10.0 \%$ on follow up test , these difference were statistically significant $(\mathrm{p}=0.001)$. Regards cut nails and hygiene, 37.0\% of caregivers done in pre test, $38.0 \%$ on post test and $92.0 \%$ done on follow up test. With statistically significant differences $(\mathrm{p}=0.001)$.

Table (5) : proved that more than one third of caregivers use clean heated water in pre test elevated to majority on post test and $92.0 \%$ on follow up test , with statistically significant difference $(\mathrm{p}=0.001)$. Regarding use liquid soup $22.0 \%$ of caregivers done in pre test these percent increase to the majority $95.0 \%$ on post test and then decrease to $92.0 \%$ on follow up test, and these difference were statistically significant $(\mathrm{p}=0.001)$. Regarding to use alcohol after hands washing only $2.0 \%$ of caregivers done then elevated to $9.0 \%$ on post test decreases to $5.0 \%$ on follow up test, only $0.3 \%$ of caregivers rub fingers circular in per test, these percent elevated to $99.0 \%$ on post test, and become $90.0 \%$ on follow up test. There with statistically significant difference $(\mathrm{p}=$ 0.001). Regarding other practices, with statistically significance difference $(\mathrm{p}=0.001)$

Table (6) : proved that the scores of caregivers attitude in pre test, post test and follow up test after educational intervention, with statistically significant difference regarding attitude of caregivers in pre test, post test and follow up test $(\mathrm{P}=0.001)$.

Figure (1) : scoring of caregiver's knowledge of parasitic infestation in pre/ post test and follow up test of educational intervention. With highly statistical significant difference between caregivers practice and personal hygiene in pre test/ post test and follow up test $(\mathrm{p}=0.001)$.

Figure (2): scores of caregiver's knowledge about food sanitation in pre test, post test and follow up test of educational intervention, with high statistically significant differences between care givers about parasitic and food sanitation, $(\mathrm{p}=0.001)$ in pre- test post test and follow up test.

Figure (3): scores of caregivers practice about food sanitation in pre test, post test and follow up test of educational intervention. Regarding food sanitation only $(1.0 \%)$ of caregivers have good score in pre test increased to $87.0 \%$ on post test and decrease again to $57.0 \%$ on follow up test, with highly statistically significant differences $(\mathrm{p}=0.001)$, with highly statistical significant difference between caregivers practice of food sanitation With highly statistical significant difference between caregivers practice and food sanitation in pre test/ post test and follow up test $(\mathrm{p}=0.001)$.

Figure (4): scores of caregivers practice about personal hygiene in pre test, post test and follow up test of educational intervention. With highly statistical significant difference between caregivers practice and personal hygiene in pre test/ post test and follow up test $(\mathrm{p}=0.001)$. 
Table (1): Distribution of demographic characteristics for caregivers and school children, $n=100$

\begin{tabular}{|c|c|c|}
\hline Items & No & $\%$ \\
\hline \multirow{2}{*}{$\begin{array}{l}\text { Child age } \\
\text { 6- } \\
\text { Up to 7-8 } \\
\text { Mean } \pm \text { SD } \\
\end{array}$} & $\begin{array}{l}12 \\
88\end{array}$ & $\begin{array}{l}12.0 \\
88.0\end{array}$ \\
\hline & \multicolumn{2}{|c|}{$6.9 \pm 0.6$ years $(5-8)$} \\
\hline $\begin{array}{l}\text { Gender of child } \\
\text { Male } \\
\text { Female }\end{array}$ & $\begin{array}{l}54 \\
46\end{array}$ & $\begin{array}{l}54.0 \\
46.0\end{array}$ \\
\hline $\begin{array}{l}\text { Number of siblings: } \\
1-3 \\
4-6 \\
7-10\end{array}$ & $\begin{array}{l}42 \\
48 \\
10\end{array}$ & $\begin{array}{l}42.0 \\
48.0 \\
10.0\end{array}$ \\
\hline Mean \pm SD & \multicolumn{2}{|c|}{$4.1 \pm 1.7$ years $(1-10)$} \\
\hline \multirow[t]{2}{*}{$\begin{array}{l}\text { Birth order: } \\
\text { 1-3 First } \\
\text { In the middle 4-6 } \\
\text { 7-10 Last } \\
\text { Mean } \pm \text { SD }\end{array}$} & $\begin{array}{l}65 \\
25 \\
10\end{array}$ & $\begin{array}{l}65.0 \\
25.0 \\
10.0\end{array}$ \\
\hline & \multicolumn{2}{|c|}{ 3.1 \pm 2.1 years } \\
\hline \multirow[t]{2}{*}{$\begin{array}{l}\text { Age of mother } \\
20- \\
30- \\
40- \\
\text { Mean } \pm \text { SD }\end{array}$} & $\begin{array}{l}26 \\
51 \\
23\end{array}$ & $\begin{array}{l}26.0 \\
51.0 \\
23.0\end{array}$ \\
\hline & \multicolumn{2}{|c|}{$\frac{1}{34.2 \pm 7.1 \text { years }(22-25)}$} \\
\hline $\begin{array}{l}\text { Residence } \\
\text { Urban } \\
\text { Semi urban }\end{array}$ & $\begin{array}{l}59 \\
41\end{array}$ & $\begin{array}{l}59.0 \\
41.0\end{array}$ \\
\hline $\begin{array}{l}\text { Caregivers education } \\
\text { Illiterate } \\
\text { Basic } \\
\text { Secondary } \\
\text { University or Higher }\end{array}$ & $\begin{array}{l}45 \\
10 \\
29 \\
16\end{array}$ & $\begin{array}{l}45.0 \\
10.0 \\
29.0 \\
16.0\end{array}$ \\
\hline $\begin{array}{l}\text { Caregivers job } \\
\text { worker } \\
\text { House wife } \\
\end{array}$ & $\begin{array}{l}27 \\
73 \\
\end{array}$ & $\begin{array}{l}27.0 \\
73.0 \\
\end{array}$ \\
\hline $\begin{array}{l}\text { Father education } \\
\text { Illiterate } \\
\text { Basic } \\
\text { Secondary } \\
\text { University or Higher } \\
\end{array}$ & $\begin{array}{l}28 \\
17 \\
36 \\
19 \\
\end{array}$ & $\begin{array}{l}28.0 \\
17.0 \\
36.0 \\
19.0\end{array}$ \\
\hline $\begin{array}{l}\text { Income } \\
<399 \\
400-799 \\
\text { More }(800) \\
\end{array}$ & $\begin{array}{l}32 \\
38 \\
30\end{array}$ & $\begin{array}{l}32.0 \\
38.0 \\
30.0\end{array}$ \\
\hline
\end{tabular}


Table (2): Distribution of environmental housing sanitation no=100

\begin{tabular}{|l|c|c|}
\hline \multicolumn{1}{|c|}{ Items } & No & $\%$ \\
\hline Lighting(electricity) & & \\
Present & 97 & 97.0 \\
Absent & 3 & 3.0 \\
\hline Housing ventilation & 89 & 89.0 \\
Present & 11 & 11.0 \\
$\quad$ Absent & & \\
\hline Sources of water & 94 & 94.0 \\
Tap & 6 & 6.0 \\
Pump & 93 & 93.0 \\
\hline Source of drinking water & 5 & 5.0 \\
Drinking directly from the tap & 1 & 1.0 \\
Connect filter in the tap & 1 & 1.0 \\
Boil water before drinking & & \\
Mineral water or distilled & 19 & 19.0 \\
\hline Bath room type & 81 & 81.0 \\
$\quad$ Modern & & \\
Ordinary & 61 & 61.0 \\
\hline Sources of water in toilet & 39 & 39.0 \\
$\quad$ From tap directly & & \\
In the container or utensil & 92 & 92.0 \\
\hline Presence of sewage in the home & 8 & 8.0 \\
$\quad$ Present & & \\
Not present & &
\end{tabular}

Table (3): Distribution of housing conditions, (presence of animals/animal waste disposal, rubbish disposal and sanitary condition), $n=100$

\begin{tabular}{|l|c|c|}
\hline \multicolumn{1}{|c|}{ Items } & No & \% \\
\hline Presence of animals at home & & \\
Yes & 53 & 53.0 \\
No & 47 & 47.0 \\
\hline Animal waste disposal & 32 & \\
$\quad$ Collect at the front in the home & 17 & 60.4 \\
In the Farm & 4 & 7.5 \\
By governmental cars & & \\
\hline Presence of basket for home trash(rubbish) & 32 & 32.0 \\
Present & 68 & 68.0 \\
Not present & & \\
If present it & 4.0 & 12.5 \\
Covered & 28.0 & 87.5 \\
Un covered & & \\
\hline When dispose the home trash(rubbish) & 54 & 54.0 \\
Daily & 35 & 35.0 \\
Day after day & 11 & 11.0 \\
Weekly & & \\
\hline Housing sanitary conditions & 61 & 61.0 \\
Bad & 32 & 32.0 \\
Good & 7 & 7.0 \\
\hline Very good & & \\
\hline
\end{tabular}


Table (4): the difference between pre / post test and follow up test among care givers regarding practices of personal hygiene, $n=100$

\begin{tabular}{|c|c|c|c|c|c|c|c|c|}
\hline$\overline{\text { Practice }}$ & \multicolumn{2}{|c|}{ Pre-test } & \multicolumn{2}{|c|}{ post -test } & \multicolumn{2}{|c|}{$\begin{array}{c}\text { Follow up - } \\
\text { test }\end{array}$} & $\overline{X^{2}}$ & $\overline{\mathbf{P}}$ \\
\hline & $\overline{\text { No }}$ & $\overline{\%}$ & $\overline{\text { No }}$ & $\overline{\%}$ & $\overline{\text { No }}$ & $\overline{\%}$ & & \\
\hline $\begin{array}{l}\text { - Wash hands betore preparing food } \\
\text {-Done } \\
\text {-Not done }\end{array}$ & $\begin{array}{l}67 \\
33\end{array}$ & $\begin{array}{l}67.0 \\
33.0\end{array}$ & $\begin{array}{c}95 \\
5\end{array}$ & $\begin{array}{c}95.0 \\
5.0\end{array}$ & $\begin{array}{l}79 \\
21\end{array}$ & $\begin{array}{l}79.0 \\
21.0\end{array}$ & 76.1 & $0.001 * *$ \\
\hline $\begin{array}{l}\text { - Washing hands before eating } \\
\text {-Done } \\
\text { - Not done }\end{array}$ & $\begin{array}{l}40 \\
60\end{array}$ & $\begin{array}{l}40.0 \\
60.0\end{array}$ & $\begin{array}{c}99 \\
1\end{array}$ & $\begin{array}{c}99.0 \\
1.0\end{array}$ & $\begin{array}{l}45 \\
55\end{array}$ & $\begin{array}{l}45.0 \\
55.0\end{array}$ & 92.8 & $0.001 * *$ \\
\hline $\begin{array}{l}\text { 3- Washing hands after eating } \\
\text {-Done } \\
\text {-Not done }\end{array}$ & $\begin{array}{l}52 \\
48\end{array}$ & $\begin{array}{l}52.0 \\
48.0\end{array}$ & $\begin{array}{c}99 \\
1\end{array}$ & $\begin{array}{c}99.0 \\
1.0\end{array}$ & $\begin{array}{l}46 \\
54\end{array}$ & $\begin{array}{l}46.0 \\
54.0\end{array}$ & 92.5 & $0.001 * *$ \\
\hline $\begin{array}{l}\text { - Washing hands after leave the toilet } \\
\text {-Done } \\
\text { - Not done }\end{array}$ & $\begin{array}{l}47 \\
53 \\
\end{array}$ & $\begin{array}{l}47.0 \\
53.0 \\
\end{array}$ & $\begin{array}{c}99 \\
1 \\
\end{array}$ & $\begin{array}{c}99.0 \\
1.0 \\
\end{array}$ & $\begin{array}{l}60 \\
40 \\
\end{array}$ & $\begin{array}{l}60.0 \\
400 .\end{array}$ & 78.6 & $0.001 * *$ \\
\hline $\begin{array}{l}\text {-Washing hands after leave the toilet } \\
\text {-With water only } \\
\text {-With soap and water } \\
\text {-Use disinfectant solution }\end{array}$ & $\begin{array}{l}36 \\
54 \\
10\end{array}$ & $\begin{array}{l}36.0 \\
54.0 \\
10.0\end{array}$ & $\begin{array}{c}20 \\
75 \\
5\end{array}$ & $\begin{array}{c}20.0 \\
75.0 \\
5.0\end{array}$ & $\begin{array}{c}66 \\
30 \\
4\end{array}$ & $\begin{array}{c}66.0 \\
30.0 \\
4.0\end{array}$ & 61.6 & $0.001 * *$ \\
\hline $\begin{array}{l}\text { - washing hands after dispose home } \\
\text { and animals wastes } \\
\text { - Done } \\
\text { - Not done }\end{array}$ & $\begin{array}{c}6 \\
94 \\
\end{array}$ & $\begin{array}{c}6.0 \\
94.0\end{array}$ & $\begin{array}{l}29 \\
71 \\
\end{array}$ & $\begin{array}{l}29.0 \\
71.0\end{array}$ & $\begin{array}{l}90 \\
10\end{array}$ & $\begin{array}{l}90.0 \\
10.0\end{array}$ & 155.1 & $0.001 * *$ \\
\hline $\begin{array}{l}\text { - Dried hands after washing } \\
\text {-Done } \\
\text {-No done }\end{array}$ & $\begin{array}{l}59 \\
41 \\
\end{array}$ & $\begin{array}{l}59.0 \\
41.0\end{array}$ & $\begin{array}{c}95 \\
5 \\
\end{array}$ & $\begin{array}{c}95.0 \\
5.0\end{array}$ & $\begin{array}{l}80 \\
20 \\
\end{array}$ & $\begin{array}{l}80.0 \\
20.0\end{array}$ & 38.1 & $0.001 * *$ \\
\hline $\begin{array}{l}\text { - Cut down nail and cleansed } \\
\text { - Done } \\
\text { - Not done }\end{array}$ & $\begin{array}{l}17 \\
83\end{array}$ & $\begin{array}{l}17.0 \\
83.0\end{array}$ & $\begin{array}{l}38 \\
62\end{array}$ & $\begin{array}{l}38.0 \\
62.0\end{array}$ & $\begin{array}{c}92 \\
8\end{array}$ & $\begin{array}{c}92.0 \\
8.0\end{array}$ & 119.8 & $0.001 * *$ \\
\hline
\end{tabular}

Table (5): the difference between pre / post test and follow up test among caregivers regarding hand washing practices, $n=100$

\begin{tabular}{|c|c|c|c|c|c|c|c|c|}
\hline Practice & \multicolumn{2}{|c|}{ Pre-test } & \multicolumn{2}{|c|}{ post-test } & \multicolumn{2}{|c|}{ Follow up -tes } & $X^{2}$ & $\mathbf{P}$ \\
\hline & No & $\%$ & No & $\%$ & No & $\%$ & & \\
\hline $\begin{array}{l}\text {-Done } \\
\text { - Not done }\end{array}$ & $\begin{array}{l}37 \\
63\end{array}$ & $\begin{array}{l}37.0 \\
63.0\end{array}$ & $\begin{array}{c}79 \\
3\end{array}$ & $\begin{array}{c}97.0 \\
3.0\end{array}$ & $\begin{array}{c}92 \\
8\end{array}$ & $\begin{array}{c}92.0 \\
8.0\end{array}$ & 119.2 & $0.001 * *$ \\
\hline $\begin{array}{l}\text { - Use liquid soap : } \\
\text {-Done } \\
\text { - Not done }\end{array}$ & $\begin{array}{l}22 \\
78\end{array}$ & $\begin{array}{l}22.0 \\
78.0\end{array}$ & $\begin{array}{c}95 \\
5\end{array}$ & $\begin{array}{c}95.0 \\
5.0\end{array}$ & $\begin{array}{c}92 \\
8\end{array}$ & $\begin{array}{c}92.0 \\
8.0\end{array}$ & 180.1 & $0.001 * *$ \\
\hline $\begin{array}{l}\text { - Use alcohol after washing hands } \\
\text {-Done } \\
\text { - Not done }\end{array}$ & $\begin{array}{c}2 \\
98\end{array}$ & $\begin{array}{l}2.0 \\
98\end{array}$ & $\begin{array}{c}9 \\
91\end{array}$ & $\begin{array}{c}9.0 \\
91.0\end{array}$ & $\begin{array}{c}5 \\
95\end{array}$ & $\begin{array}{c}5.0 \\
95.0\end{array}$ & 12.6 & $0.001 * *$ \\
\hline $\begin{array}{l}\text { - Rub fingers circled } \\
\text {-Done } \\
\text { - Not done }\end{array}$ & $\begin{array}{c}3 \\
97\end{array}$ & $\begin{array}{c}3.0 \\
97.0\end{array}$ & $\begin{array}{c}99 \\
1\end{array}$ & $\begin{array}{c}99.0 \\
1.0\end{array}$ & $\begin{array}{l}90 \\
10\end{array}$ & $\begin{array}{l}90.0 \\
10.0\end{array}$ & 244.01 & $0.001 * *$ \\
\hline $\begin{array}{l}\text { - Rubbed between the fingers } \\
\text {-Done } \\
\text { - Not done }\end{array}$ & $\begin{array}{c}2 \\
98\end{array}$ & $\begin{array}{c}2.0 \\
98.0\end{array}$ & $\begin{array}{c}99 \\
1\end{array}$ & $\begin{array}{c}99.0 \\
1.0\end{array}$ & $\begin{array}{l}90 \\
10\end{array}$ & $\begin{array}{l}90.0 \\
10.0\end{array}$ & 248.3 & $0.001 * *$ \\
\hline
\end{tabular}




\begin{tabular}{|c|c|c|c|c|c|c|c|c|}
\hline Practice & \multicolumn{2}{|c|}{ Pre-test } & \multicolumn{2}{|c|}{ post-test } & \multicolumn{2}{|c|}{ Follow up -tes } & $\mathrm{X} 2$ & $\mathbf{P}$ \\
\hline & No & $\%$ & No & $\%$ & No & $\%$ & & \\
\hline $\begin{array}{l}\text {-Rub your nails and under nails } \\
\text { with soft braches } \\
\text {-Done } \\
\text { - Not done }\end{array}$ & $\begin{array}{c}3 \\
97\end{array}$ & $\begin{array}{c}3.0 \\
97.0\end{array}$ & $\begin{array}{c}96 \\
4\end{array}$ & $\begin{array}{c}96.0 \\
4.0\end{array}$ & $\begin{array}{l}90 \\
10\end{array}$ & $\begin{array}{l}90.0 \\
10.0\end{array}$ & 232.4 & $0.001 * *$ \\
\hline $\begin{array}{l}\text {-Rinse hands under running } \\
\text { water after specification for } \mathbf{2 0} \\
\text { second } \\
\text {-Done } \\
\text { - Not done }\end{array}$ & $\begin{array}{l}17 \\
83\end{array}$ & $\begin{array}{l}17.0 \\
83.0\end{array}$ & $\begin{array}{c}99 \\
1\end{array}$ & $\begin{array}{c}99.0 \\
1.0\end{array}$ & $\begin{array}{c}92 \\
8\end{array}$ & $\begin{array}{c}92.0 \\
8.0\end{array}$ & 194.3 & $0.001 * *$ \\
\hline $\begin{array}{l}\text { - Drying your hands by toilet } \\
\text { paper } \\
\text {-Done } \\
\text { - Not done }\end{array}$ & $\begin{array}{c}3 \\
97\end{array}$ & $\begin{array}{c}3.0 \\
97.0\end{array}$ & $\begin{array}{l}22 \\
78\end{array}$ & $\begin{array}{l}22.0 \\
78.0\end{array}$ & $\begin{array}{l}30 \\
70\end{array}$ & $\begin{array}{l}30.0 \\
70.0\end{array}$ & 25.6 & $0.001 * *$ \\
\hline
\end{tabular}

Table (6): Scores of caregivers attitude about safety food in pre test / post test and follow up test of educational intervention, $\mathrm{n}=100$

\begin{tabular}{|c|c|c|c|c|c|c|c|c|}
\hline Attitude & \multicolumn{2}{|c|}{ Pre- test } & \multicolumn{2}{c|}{ post- test } & \multicolumn{2}{c|}{ Fallow- up test } & Fisher exact & P \\
\hline \multirow{2}{*}{ Positive } & No & $\%$ & No & $\%$ & No & $\%$ & \multirow{2}{*}{41.3} & $0.001^{* *}$ \\
\cline { 2 - 7 } & 75 & 75.0 & 96 & 96.0 & 100 & 100.0 & & \\
\hline Negative & 25 & 25.0 & 4 & 4.0 & 0 & 0.0 & & \\
\hline
\end{tabular}

Figure (1): scoring of caregiver's knowledge of parasitic infestation in pre/ post test and follow up test of educational intervention.

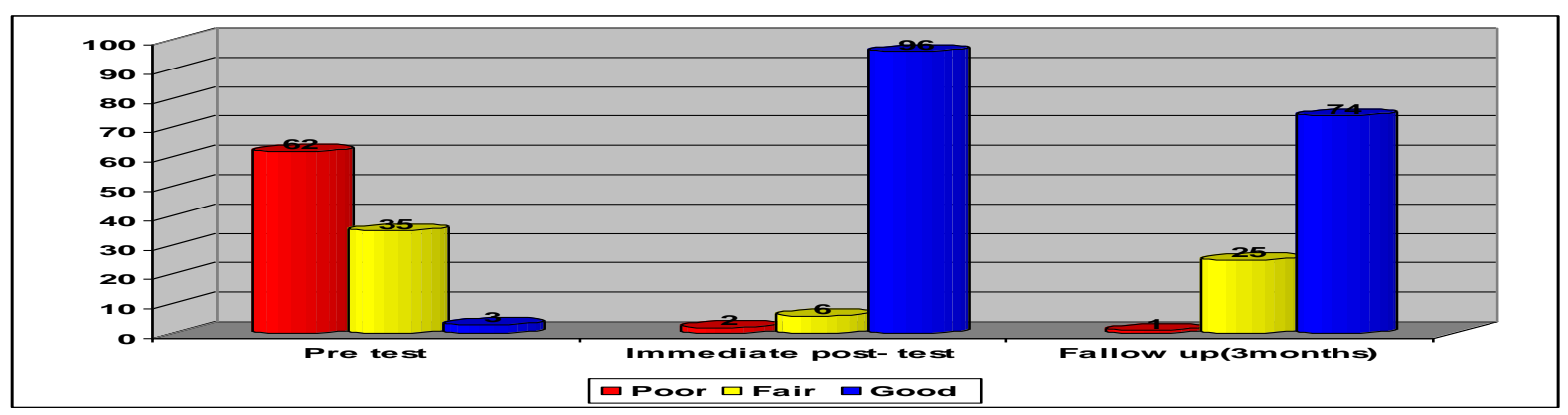

Figure (2): scores of caregiver's knowledge about food sanitation in pre test, post test and follow up test of educational intervention

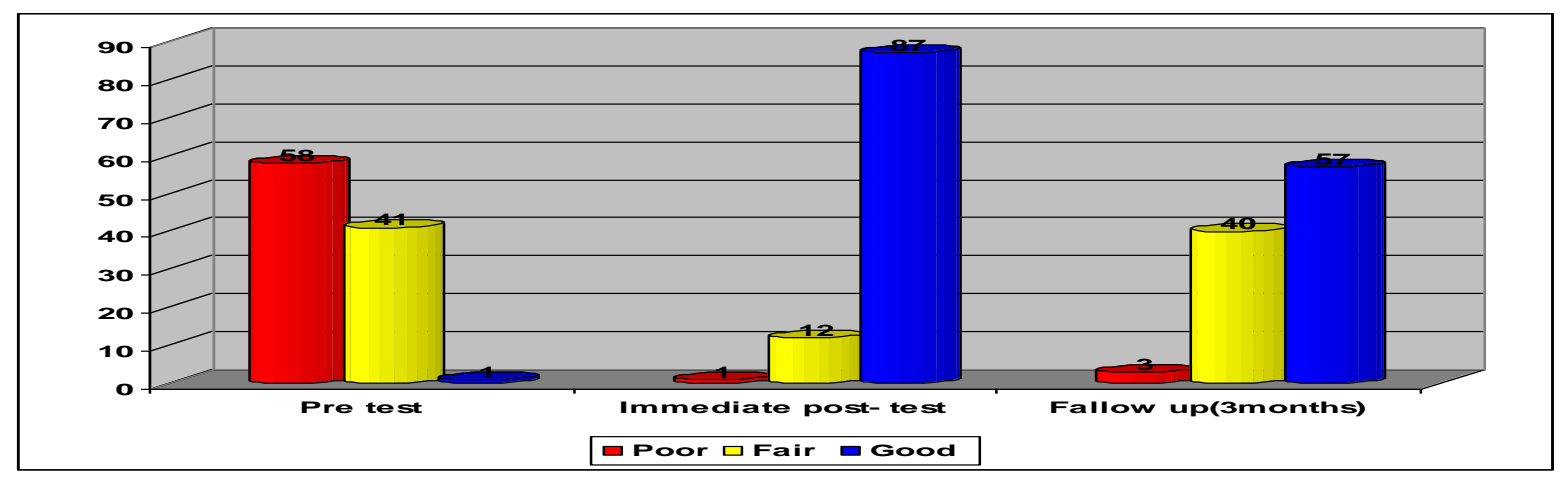


Figure(3): scores of caregivers practice about food sanitation in pre test, post test and follow up test of educational intervention.

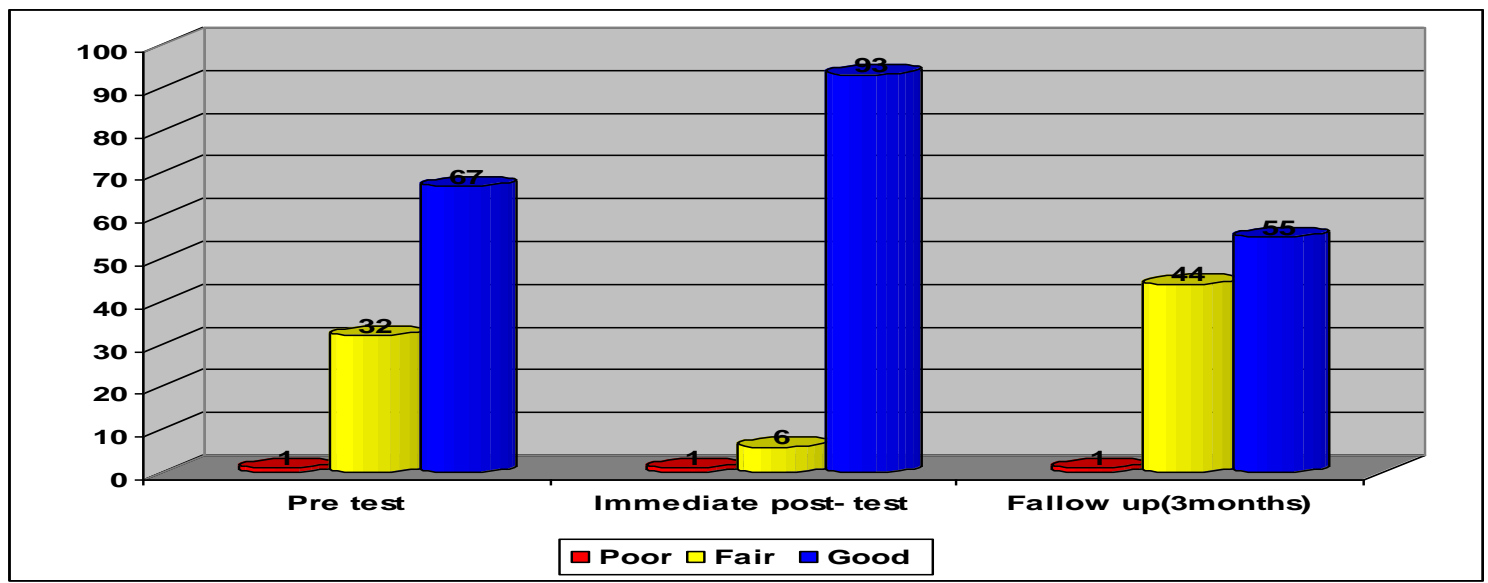

Figure (4): scores of caregivers practice about personal hygiene in pre test, post test and follow up test of educational intervention

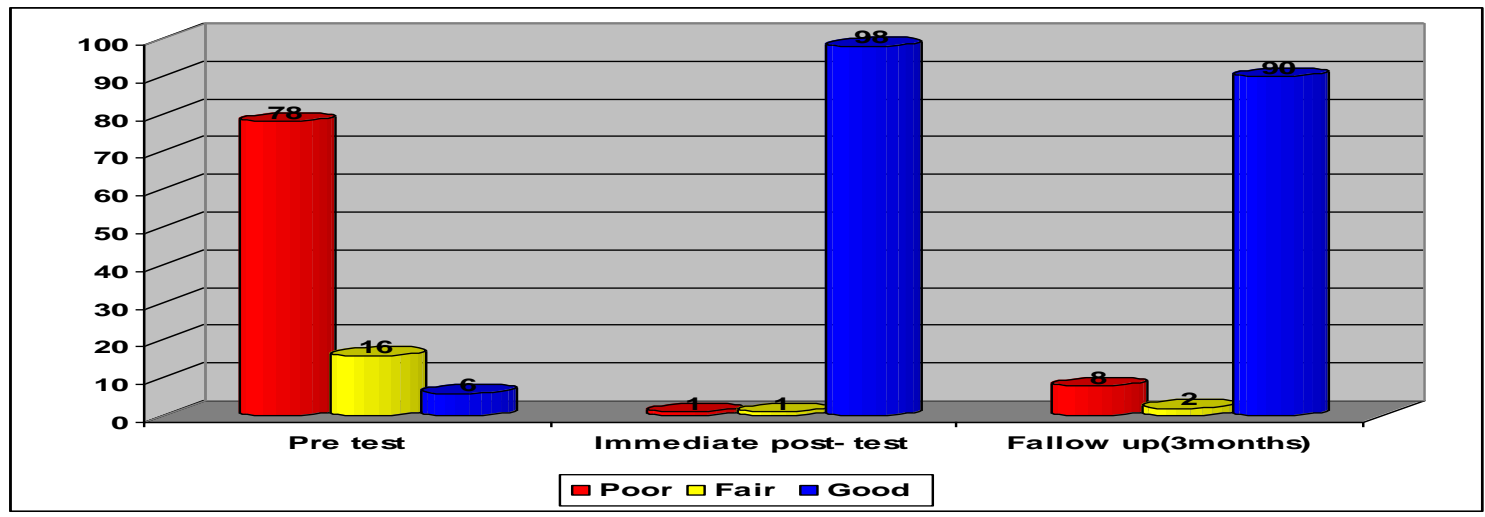

\section{Discussion:}

School children are considered one of the vulnerable group of population due to their continuous growth and development at all levels. They are a vulnerable group and great attention should be paid to tackle the health problem of intestinal infestations (Bhalawar et al., 2009and Belizario et al., 2010)

Less than three quarters of mothers were house wives while only $5.0 \%$ un-employed. As regards to the income more than one third of the caregivers earn for 400-799 pounds a month and $30.0 \%$ of them earn more than 800 pounds/ month, this results are similar with Mahmoud, (2000) \& EL- Masry et al., (2010) in Sohag governorate who showed that low social classes were significant risk factors for intestinal infestations.

Concerning distribution of environmental housing sanitation presented in $(\mathrm{tab}, 2)$ it was clear that the majority of houses have electricity source, and $89 \%$ present ventilation in the house, regarding the source of water in the house majority of caregivers are using the tap water, and minority of them are using the pump water, most of the caregivers drinking water directly from the tap, and only $1.0 \%$ of them boiling the water before drinking it, and also the same number of them drinking the distilled water, related to the type of toilet, more than three quarter of the caregivers using ordinary toilet and $19.0 \%$ using modern toilet, in spite off low percent but presence dangerous on the health, this might be interpreted that using the modern toilet may contribute to spread of infection with intestinal infestations.

This results are accordance with Cuevas et al.,(2007) and Jombo,\& Akosu, (2007) were noticed that it is already known that environmental sanitation and hygienic practices have been associated with the incidence of intestinal infestations, improved water supply and the use of toilet facilities have contributed to the reduction of infections with intestinal infestations. 
Regarding the source of water in the toilet, about two thirds of the caregivers using the tap water directly in the toilet, while more than one third of them are using the water in the container, regarding the sewage highly present in the house, and only $8.0 \%$ not present. Intestinal infestation depends on the hygiene and sanitation of people involved, water contamination, health education status etc. The caregivers and children were advised to treat the well water prior to consumption either by filtering or boiling or both. This finding is consistent with Shrestha, (2002) who reported a higher rate of intestinal infestation in general school going children les than three quarter compared to boarding school going children less than half and $40 \%$ who used the latrines built by Family Planning Association Nepal, in Kathmandu and Sunsari respectively

As regards distribution of environmental housing conditions, the current result presented in table (3) it was revealed that more than two third of the caregivers don't use any basket or container for home trash, most of those baskets did not covered. Regarding frequency of home trash disposal more than half of the caregivers dispose the trash daily and only more than one tenth weekly this results may be interpreted that the housing condition may contribute and assist the spread of infection with intestinal infestations this result is consistent with Abordo et al., (2010) who stated that all caregivers frequently adhered to some garbage disposal practices, in their homes, they would use garbage containers and place them away from the reach of animals, food and water containers. Regarding housing sanitary condition about two third of houses present bad, about one third good and only $7.0 \%$ very good housing sanitary conditions.accordance withWHOwho reported that standard score about environment and housing sanitation.

Concerning to hand washing practices the current study illustrated that more than two thirds of the caregivers washing hands before preparing the food in per test then increases to the majority on post test and decreases again to more than three quarter after follow up test, with statistically significant difference $(p=0.001)$.also less than half of the caregivers washing hands before eating in pre test increase to the most on post test, and slightly decease after follow up, with statistically significant differences $(\mathrm{p}=0.001)$

This finding in consistent with Campos et al., (2009), who found that about three quarter of caregivers did not receive periodic training, more than half did not undergo annual health examinations and all did not practice proper hand hygiene, a situation that reflected significantly $\mathrm{p}<0.05$ in hand contamination, in which fecal coli forms were detected on $55.6 \%$ of the hands analyzed, who concluded that the schools studied did not have appropriate hygienic conditions, suggesting the need for interventions that ensure the quality of houses of the caregivers of school children.

As regards use liquid soap for hand washing more than one quarter of the caregivers are using it in pre test these percent increase to the majority on post test and then slightly decrease

after follow up test, and these difference were statistically significant $(\mathrm{p}=0.001)$, this finding in the same line with Fung and Cairncross, (2009) who found that hand washing with soap may be one of the most cost-effective means of preventing intestinal infestations in developing countries.

This study reveled that more than one third of the caregivers wash hands with water only, more than half with water and soap, only one tenth use disinfected solution in pre test while used soap and water elevated to most on post test, with statistically significant differences between pre and post test $(\mathrm{p}=$ $0,001)$, more than one quarter of them rub finger circular in pre test arrive to the majority on post test and $90.0 \%$ after follow up this mean due to the educational intervention was successful in improving caregivers about hand washing practice.

These findings are consistent with study conducted by Mayo Clinic staff, (2010) who estimated that only more than one quarter of child caregivers wash hand with soap after the toilet, make plans' involving hand washing included to improve family health and to teach the caregivers and their children as hand washing with good manners. Also in the same line with Sehgal et al., (2010), who sharing with candidate strategies for promoting hand washing with soap include creating social norms, highlighting disgust of dirty hands and teaching the caregivers and their children as hand washing with soap good manners, environmental barriers were few as soap was available in almost every household, as was water, because much hand washing is habitual.

This study show that the scores of caregivers attitude about food sanitation and personal hygiene, the current study found, one quarter of the caregivers had negative attitude while three quarter had positive attitude toward food safety, with statistically significant difference in pre test, post test and follow up test of educational intervention $(\mathrm{P}=0.001)$, this result supported with Hammam et al., (2010) who reported that less than half of the caregivers had negative while more than half positive attitude toward food safety.

This study revealed that the scores of the caregivers practice about food sanitation and personal hygiene pre /post test and follow up test of educational intervention. Regarding food sanitation only one of 
the caregivers have good score before the educational intervention in pretest while improved after the (post test) increased to the most in general but slight decline in their practices after three months from the intervention. So that this findings indicated that highly statistically significant difference between caregivers practice and personal hygiene in pre test/ post test and follow up test $(\mathrm{p}=0.001)$.

\section{Conclusions:}

From the findings and research hypotheses the following could be concluded:

That the caregiver's knowledge, practices and attitudes regarding the intestinal parasitic infestations (signs and symptoms, methods of diagnosis and treatment, hygienic measures) were improved after the implementation of the educational intervention with slight decline in the knowledge and practices after three months from implementation. With highly statistically significant differences were detected.

\section{Recommendation}

Based on the results of the present study, following recommendation should be considered:-

- Health education for improving personal and environmental hygienic measures and regular screening and treatment for parasitic infestation and more studies on big number of students in rural and urban areas at Upper Egypt, and health education for primary school students regards parasitic infestation. Display posters on areas frequently visited by students, like sinks and toilets, on proper hand washing to limit or reduce, if not stop, the oral-fecal transmission of intestinal parasites.

\section{Reference}

1. Abordo I. C, Pelayo, J. L Nuñez A. A.Tagra J. A \& Militante I. C. S (2010): The Environmental Sanitation, Hygienic Practices and the Prevalence of Intestinal parasite.

2. Allender J.A., Rector C. and Warner K.D., (2010): Community Health Nursing, Promoting and protecting the public's health, unit 6, Promoting and protecting the health of aggregates with developmental needs, 7edition, 'Philadelphia, P: 608.

3. Belizario, V.Y., F.I.G. Totañes, W.U. de Leon, Y. F. Lumampao and R.N.T. Ciro. (2010): Soil-transmited helminth and other intestinal parasitic infections among school children in indigenous people communities in Davao del Norte, Philippines. doi:10.1016/j.actatropica.2011.02.010.

4. Bhalwar. R, Vaidya. R, Tilak. R, Gupta. RK, (2009): Text Book of Public Health and
Community Medicine, published by Department of community medicine, WHO, Indian office, New Delhi, Excreta Disposal, Water supply, Pp 666-80.

5. Bogitsh, BJ .Carter, CE. Oeltmnn, T, N (2013): Human parasitology, $4^{\text {th }} \mathrm{Ed}$, United state American, Medical parasitology, parasitic disease, www.elsaveir. Com

6. Borg K.T. and Ryan R.G, (2010): Parasitic Disease, Ch 149, And P: 775-781 (http://www.cdc.gov/travel/) Vo.3 N,25

7. Campos AKC, Angela Maria Soares Cardonha, et al. (2009): Assessment of personal hygiene and practices of food handlers in municipal Public schools of Natal, Brazil. Food Control, Volume 20, Issue 9, September, Pages 807-810.

8. Chan, M.S., (2004): The global burden of intestinal nematode Infections-fifty years on. Parasite. Today, Ch 13, 438-443. Chapter 3 a topic Disorders and Parasitic Infections.

9. Cuevas, F., Reyala, J., Cruz-Earnshaw, R., Bonito, S., Sitioco, J., \& Serafca, L. (2007): Public health nursing in the Philippines (10th Ed.). Manila,Philippines: Publications Commitee, National League of Philippine Government Nurses.

10. Curtale, F, Pezzotti, P, Sharbini, A., Almaadat, H., Saad, Y. S., and Babille M.,(2009): Health policy and planning; 13(4): 423^432 Oxford University Press Knowledge, perceptions and behavior of mothers toward intestinal helminths in Upper Egypt: International Course for Health Managers, Institute Superior di Sanita, Rome, Italy, laboratory of Epidemiology and Biostatistics, 3Strengthening Rural health Services Project, Ministry of Health, Qena, Egypt, and Directorate General for Development.

11. El-Masry H. M.; Ahmed Y. A.; Hassan A. A.; Zaky S, Abd-Allah E. S. El-Moselhy E. A.; Baraka Y. A. And Abdel-Rahem M. A (2010) : Prevalence, Risk Factors and Impacts of Schistosomal and Intestinal Parasitic Infections among Rural School Children in Sohag Governorate .Departments of Pediatrics; Tropical Medicine; Community Health Nursing; Community Medicine and Parasitology Faculty of Medicine and Nursing, Al-Azhar and Zagazig University

12. Erko, B and Legesse, M.(2004): Prevalence of intestinal parasites among rural area close to the southeast of Lake Langano, Ethiopi schoolchildren institute of Pathobiology, Addis Ababa University, P.O. Box 1176, E-mail: aauipb@telecom.net.et, Addis Ababa P.p 60-64. 
13. Fung IC, Cairncross S. (2009): Ascariasis and hand washing. Trans R Soc Trop Med Hyg. Mar; 103(3):215-22. Department of Infectious Disease Epidemiology, Imperial College London, St Mary's campus, Norfolk Place, London W2 1PG, UK.

14. Hammam HM, Zarzour AH, Moftah FM, Abdel-Aty MA, Hany AH, El-Kady AY, Nasr AM, Abd-El-Samie A, Qayed MH, Mikhail NH, Talaat $M$ and Hazrati tappeh, Kh., Mohammadzadeh., H., Nejad Rahim, R., Barazesh, A., Khashaveh ., Sh,Taherkhani (2010): Prevalence of Intestinal Parasitic Infections among Mentally Disabled Children and Adults of Urmia, Iran, Dept. Of Parasitology \& Mycology, Faculty of Medicine, Urmia University of Medical Sciences, Urmia, Iran Infectious disease specialist, Dept. Of Infectious Disease, Taleghani Hospital, Urmia Medical University.

15. Hazrati tappeh, Kh., Mohammadzadeh., H., Nejad Rahim, R., Barazesh, A., Khashaveh., Sh,Taherkhani (2010): Prevalence of Intestinal Parasitic Infections among Mentally Disabled Children and Adults of Urmia, Iran, Dept. Of Parasitology \& Mycology, Faculty of Medicine, Urmia University of Medical Sciences, Urmia, Iran Infectious disease specialist, Dept. Of Infectious Disease, Taleghani Hospital, Urmia Medical University.

16. Horne PD (2002): First evidence of enterobiasis in ancient Egypt. J. Parasitol., 88:1019-21.

17. Jombo, G., Egah, D., \& Akosu, J. (2007): Intestinal parasitism, potable water availability and methods of sewage disposal in three communities in Benue State, Nigeria: A survey. Annals of African Medicine, 6(1), 17-21.

18. Mahmoud AF (2000): Parasitic infections. In: Nelson text book of pediatrics. WB Saunders Company, Philadelphia.

19. Mayo Clinic staff, (2010): Hand washing: dos and don'ts. Retrieved from http://www.mayoclinic.com/health/handwashing/HQ00407.

20. Mayo Foundation for Medical Education and Research (MFMER). (1998-2013): All rights reserved. A single copy of these materials may be reprinted for noncommercial personal use only. "Mayo," "Mayo Clinic," "MayoClinic.com," "Embody Health," "Enhance your life," and the triple-shield Mayo Clinic logo are trademarks of Mayo Foundation for Medical Education and Research.

21. Mehraj, K.V. Hatcher, J. Akhtar, S. Rafique, G. Beg, M A (2008): Department of Pathology \& Microbiology, Aga Khan University Pakistan,
Prevalence and Factors Associated with Intestinal Parasitic Infection among Children in an Urban Slum of Karachi, PLoS ONE | www.plosone.org November, V 3, N 11, PP.1-6.

22. Nies, M. A, McEwen, M, (2011): Community/ Public Health Nursing, Promoting the Health of Population, Chapter 5,Unit 2,Epidemiology, The Art and science of community Health Nursing ,5th Ed, Elsevier, Pp 77-8.

23. Sehgal R a, Gogulamudi V. Reddya, Jaco J. Verweijb, Atluri V. Subba Raoa(2010):

Prevalence of intestinal parasitic infections among school children and pregnant women in, low socio-economic area, Chandigarh, North India.a Department of Parasitology, Postgraduate Institute of Medical Education and Research, Chandigarh-160012, India.Department of Parasitology, Leiden University Medical Center, P.O. Box 9600, 2300 RC Leiden, The Netherlands *Corresponding Author:sehgalpgi@gmail.com

24. Shrestha B, (2002): Intestinal Parasitic Infestation in Healthy School Children of Llalitpur District, Lecturer, Department of Microbiology Tri-chandra College, Kathmandu, Nepal, Email: bshrestha@enet.com.np

25. WHO (2009): food safety and food born illness, media center fact sheet (737), Gen 